\title{
Application of temperature-gradient gel electrophoresis in taxonomy of coryneform bacteria
}

\author{
Andreas Felske, ${ }^{1 \dagger}$ Marc Vancanneyt, ${ }^{2}$ Karel Kersters ${ }^{2,3}$ \\ and Antoon D. L. Akkermans'
}

Author for correspondence: Andreas Felske. Tel: +3454624711 (Institute) extension 131. Fax: + 345 4624002. e-mail: Andreas@cica.es

\author{
1 Laboratory of \\ Microbiology, \\ Department of \\ Biomolecular Sciences, \\ Wageningen Agricultural \\ University, Hesselink van \\ Suchtelenweg 4, $6703 \mathrm{CT}$ \\ Wageningen, The \\ Netherlands \\ 2,3 BCCM/LMG Culture \\ Collection ${ }^{2}$ and \\ Laboratory of \\ Microbiology3, University \\ of Ghent, K.-L. \\ Ledeganckstraat 35, \\ B-9000 Ghent, Belgium
}

\begin{abstract}
Strains belonging to the Gram-positive coryneform soil bacteria were screened genotypically by temperature-gradient gel electrophoresis (TGGE). This method allows the sequence-specific separation of amplified fragments of 165 rRNA genes. A total of 115 reference strains representing the majority of the species of the genera Aeromicrobium, Agromyces, Arthrobacter, Aureobacterium, Cellulomonas, Curtobacterium, Nocardioides and Terrabacter were characterized. Depending on the genus investigated, the resolution limit of the technique appeared to be at the species or genus level or intermediate between the two. Aberrant TGGE profiles of strains within particular taxa revealed genomic heterogeneity and generic misclassification of nine strains studied. Beyond that, indications of 165 rRNA gene heterogeneity were found within the genomes of three Curtobacterium strains. The misclassifications revealed by TGGE were confirmed using whole-cell fatty acid methyl ester analysis and subsequent comparison with a database. TGGE has been demonstrated to be a useful tool in bacterial taxonomy.
\end{abstract}

Keywords: temperature-gradient gel electrophoresis, coryneform bacteria, 16S rDNA gene heterogeneity, fatty acid methyl ester

\section{INTRODUCTION}

In recent years, molecular methods have been used increasingly to characterize prokaryotes, because bacterial diversity cannot be described solely by morphological and physiological features, which can be common to bacteria from phylogenetically distant taxa. On the other hand, closely related genera may show a rich morphological and physiological diversity. The coryneform bacteria, on which this paper focuses, and their entire class, Actinobacteria, are good examples in this context (Stackebrandt et al., 1997). The modern molecular taxonomy of bacteria follows the polyphasic strategy of classification (Colwell, 1970; Vandamme et al., 1996), in which different approaches are applied simultaneously. Chemotaxonomic information is collected by analysing the composition of particular cell constituents, such as peptidoglycans,

†Present address: Instituto de Recursos Naturales y Agrobiologia, CSIC, Apartado 1052, 41080 Seville, Spain.

Abbreviations: DGGE, denaturing-gradient gel electrophoresis; FAME, fatty acid methyl ester; TGGE, temperature-gradient gel electrophoresis. fatty acids and polar lipids. Another popular approach is based on DNA base composition. Analysis of DNA-DNA reassociation kinetics can discriminate closely related species (Stackebrandt \& Kandler, 1979) and can be used to determine the boundaries of prokaryote species (Schleifer \& Stackebrandt, 1983). In contrast, bacterial phylogeny is nowadays correlated with the phylogeny of their 16S rRNA, as described by Woese \& Fox (1977).

Another tool within the arsenal of this polyphasic strategy could be the highly specific, partial analysis of 16S rRNA sequences by temperature-gradient gel electrophoresis (TGGE) (Rosenbaum \& Riesner, 1987) or the similar method, denaturing-gradient gel electrophoresis (DGGE) (Fischer \& Lerman, 1979). These powerful techniques have been applied particularly to the analysis of $16 \mathrm{~S}$ rRNA in the area of molecular ecology (Muyzer et al., 1993; Ferris et al., 1996; Rölleke et al., 1996; Teske et al., 1996; Felske et al., 1997), but not in taxonomy. Buchholz-Cleven et al. (1997) found DGGE to be convenient and reliable in the analysis of unidentified isolates before sequencing. Here we report on the application of TGGE for 
Table 1. List of all 115 strains investigated and their TGGE signals (as compiled in Fig. 1)

Bands are indicated only if there was more than one per lane. Bold strains are represented in Fig. 1.

\begin{tabular}{|c|c|c|}
\hline Genus/lane & Band & Strain \\
\hline \multicolumn{3}{|l|}{ Aeromicrobium } \\
\hline \multirow[t]{2}{*}{ Lane $A e$} & el & Aeromicrobium fastidiosum LMG $16205^{\mathrm{T}}$ \\
\hline & e2 & Aeromicrobium erythreum LMG $16472^{\mathrm{T}}$ \\
\hline \multicolumn{3}{|l|}{ Agromyces } \\
\hline \multirow[t]{2}{*}{ Lane $A g$} & g1 & $\begin{array}{l}\text { Agromyces cerinus } \text { LMG }^{16155^{\mathrm{T}}} \text {, LMG } 16586, \text { LMG } 16587 \text {, } \\
\text { LMG } 16157^{\mathrm{T}} \text {; Agromyces fucosus LMG } 16156^{\mathrm{T}}, \text { LMG } 16588 \text {, } \\
\text { LMG } 16589\end{array}$ \\
\hline & $\mathrm{g} 2$ & Agromyces ramosus LMG $16680^{\mathrm{T}}$ \\
\hline \multicolumn{3}{|l|}{ Curtobacterium } \\
\hline Lane $C u$ & & $\begin{array}{l}\text { Curtobacterium albidum LMG } 8759^{\mathrm{T}} \text {; Curtobacterium citreum } \\
\text { LMG } 16240, \text { LMG } 8786^{\mathrm{T}} \text {; Curtobacterium flaccumfaciens } \\
\text { LMG } 3596^{\mathrm{T}} \text {, LMG } 7241, \text { LMG } 3645^{\mathrm{T}} \text {, LMG } 3650, \mathrm{LMG} \\
3702^{\mathrm{T}} \text {, LMG } 3704, \mathrm{LMG} 3710, \text { LMG } 3715^{\mathrm{T}} \text {; Curtobacterium } \\
\text { luteum LMG } 8787^{\mathrm{T}} ; \text { Curtobacterium pusillum LMG } 8788^{\mathrm{T}} \text {, } \\
\text { LMG } 8812\end{array}$ \\
\hline \multicolumn{3}{|r|}{ - } \\
\hline \multirow[t]{6}{*}{ Lane $A r$} & $\mathrm{r} 1$ & $\begin{array}{l}\text { Arthrobacter citreus LMG 16124, LMG } \text { 16388 }^{\text {T }} \text {; Arthrobacter } \\
\text { viscosus LMG } 16186\end{array}$ \\
\hline & $\mathrm{r} 2$ & Arthrobacter crystallopoietes LMG 3819T \\
\hline & r3 & $\begin{array}{l}\text { Arthrobacter citreus LMG 16146; Arthrobacter mysorens LMG } \\
\text { 16125, LMG 16219 ; Arthrobacter nicotianae LMG } 16126, \\
\text { LMG } 16159, \text { LMG }^{\mathrm{T}} 16305^{\mathrm{T}} ; \text { Arthrobacter protophormiae LMG } \\
\text { 16115, LMG } 16324^{\mathrm{T}} ; \text { Arthrobacter uratoxydans LMG } 16117 \text {, } \\
\text { LMG } 16129 \text {, LMG } 16220^{\mathrm{T}}\end{array}$ \\
\hline & $\mathrm{r} 4$ & 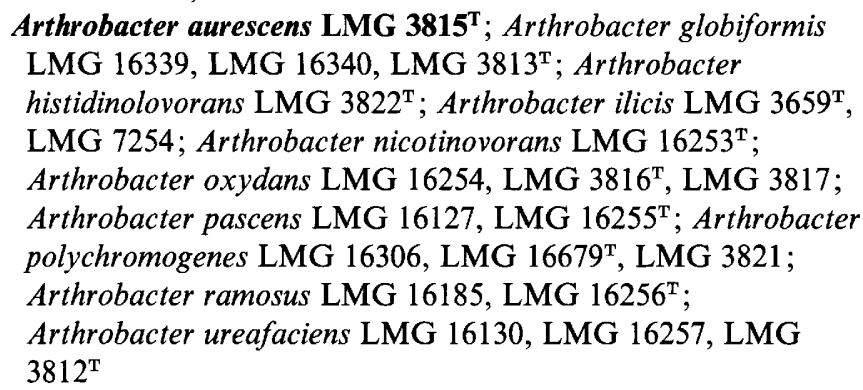 \\
\hline & r5 & Arthrobacter sulfureus LMG 16116, LMG 16128, LMG 16694'T \\
\hline & r6 & Arthrobacter atrocyaneus LMG $3814^{\mathrm{T}}$ \\
\hline Lane 1 & & Arthrobacter ilicis LMG 7255 \\
\hline Lanes $2+3$ & & Arthrobacter siderocapsulatus LMG 16118, LMG 16206T \\
\hline Lane 5 & & Arthrobacter picolinophilus LMG $16262^{\mathrm{T}}$ \\
\hline Lane 6 & & Arthrobacter globiformis LMG 3820 \\
\hline \multicolumn{3}{|l|}{ Terrabacter } \\
\hline \multirow[t]{2}{*}{ Lane $T+4$} & $\mathrm{t} 1$ & Terrabacter tumescens $\mathbf{L M G} 3818^{\mathrm{T}}$ \\
\hline & $\mathrm{t} 2$ & Terrabacter tumescens LMG 16133 \\
\hline \multicolumn{3}{|l|}{ Nocardioides } \\
\hline \multirow[t]{4}{*}{ Lane $N$} & $\mathrm{n} 1$ & Nocardioides jensenii LMG $16325^{\mathrm{T}}$ \\
\hline & $\mathrm{n} 2$ & Nocardioides simplex LMG $16261^{\mathrm{T}}$ \\
\hline & $\mathrm{n} 3$ & Nocardioides albus LMG 16212, LMG 16213, LMG 16326' \\
\hline & $\mathrm{n} 4$ & Nocardioides luteus LMG 16160, LMG 16209 ${ }^{\mathrm{T}}$ \\
\hline Lane 7 & & Nocardioides simplex LMG 3810 \\
\hline \multicolumn{3}{|l|}{ Cellulomonas } \\
\hline Lane $C e$ & $\mathrm{cl}$ & $\begin{array}{l}\text { Cellulomonas cellulans LMG 16121, LMG 16221', LMG } \\
\text { 16238, LMG 16259; Cellulomonas uda LMG 16123, LMG } \\
16327^{\mathrm{T}}\end{array}$ \\
\hline
\end{tabular}


Table 1 (cont.)

\begin{tabular}{|c|c|c|}
\hline Genus/lane & Band & Strain \\
\hline & c2 & $\begin{array}{l}\text { Cellulomonas gelida LMG } 16122 \text {, LMG } 16697^{\mathrm{T}} \text {; Cellulomonas } \\
\text { flavigena LMG } 16263^{\mathrm{T}} ; \text { C. fimi LMG } 16239, \text { LMG } \text { 16345 }^{\mathrm{T}}\end{array}$ \\
\hline & c3 & $\begin{array}{l}\text { Cellulomonas biazotea LMG } 16695^{\mathrm{T}} \text {; Cellulomonas turbata } \\
\text { LMG 16191, LMG 4072 } \text {; Cellulomonas cellasea LMG } 16323^{\mathrm{T}}\end{array}$ \\
\hline Lane 8 & & Cellulomonas fimi LMG 16132 \\
\hline Lane 9 & & Cellulomonas turbata LMG 16346 \\
\hline \multicolumn{3}{|c|}{ Aureobacterium } \\
\hline \multirow[t]{6}{*}{ Lane $A u$} & ul & Aureobacterium trichothecenolyticum LMG $16696^{\mathrm{T}}$ \\
\hline & u2 & $\begin{array}{l}\text { Aureobacterium testaceum LMG 16144, LMG 16237, LMG } \\
\text { 16344 }^{\mathrm{T}}\end{array}$ \\
\hline & u3 & $\begin{array}{l}\text { Aureobacterium terrae LMG } 16190, \text { LMG } \mathbf{1 6 4 7 1}^{\mathrm{T}} \text {; } \\
\text { Aureobacterium schleiferi LMG } 16189 ; \text { Aureobacterium } \\
\text { esteraromaticum LMG } 16187, \text { LMG } 4020^{\mathrm{T}}\end{array}$ \\
\hline & u4 & $\begin{array}{l}\text { Aureobacterium keratanolyticum LMG } 16470^{\mathrm{T}} ; \text { Aureobacterium } \\
\text { liquefaciens } \mathrm{LMG} 16120, \mathrm{LMG} 16188, \mathrm{LMG} 16342^{\mathrm{T}} \\
\text { Aureobacterium luteolum } \mathrm{LMG} 16207^{\mathrm{T}} ; \text { Aureobacterium } \\
\text { saperdae } \mathrm{LMG} 16343^{\mathrm{T}} ; \text { Aureobacterium schleiferi } \mathrm{LMG} \\
16153^{\mathrm{T}}\end{array}$ \\
\hline & u5 & Aureobacterium arabinogalactanolyticum LMG 16469T \\
\hline & u6 & Aureobacterium barkeri LMG 16142, LMG 16341 ${ }^{\mathrm{T}}$ \\
\hline
\end{tabular}

taxonomic classification of 115 coryneform bacterial strains from the $\mathrm{BCCM} / \mathrm{LMG}$ culture collection. These isolates included the majority of cultured species from the genera Aeromicrobium, Agromyces, Arthrobacter, Aureobacterium, Cellulomonas, Curtobacterium, Nocardioides and Terrabacter.

TGGE analysis starts with PCR amplification of a variable region of the $16 \mathrm{~S}$ rDNA. The technique is then used to separate double-stranded PCR products according to the melting behaviour of the molecules. DNA of different sequences migrate different distances. The PCR product generated from a pure bacterial strain normally results in a single band that migrates a specific distance. The detection of additional bands would indicate that more sequences are present in the culture due to contamination of the culture with another organism or the presence of different 16S rDNA sequences in one bacterial genome. Because of the great efficiency and speed with which the technique reveals contamination in pure cultures and 16S rRNA sequence heterogeneity (Nübel et al., 1996), TGGE is a promising tool for taxonomic studies. However, as 16S rRNA sequencing is timeconsuming and expensive to perform, it is advisable to determine in advance whether different copies of $16 \mathrm{~S}$ rRNA are present in the strain to be analysed. It is not known to what extent this phenomenon occurs among prokaryotes. Until now only a few observations of different $16 \mathrm{~S}$ rDNAs in one strain have been reported (Mylvaganam \& Dennis, 1992; Nübel et al., 1996).

The extent to which the TGGE approach yields comparative taxonomic information in the same way as chemotaxonomic fingerprinting techniques, such as cellular fatty acid analysis, or DNA fingerprinting methods, such as restriction fragment length polymorphism/amplified rDNA-restriction analysis (RFLP/ARDRA) (Vaneechoutte et al., 1992) or random amplified polymorphic DNA/arbitrarily primed PCR (RAPD/AP-PCR) (Welsh \& McClelland, 1990), remains to be determined. The other DNA methods reveal more or less complex band patterns for one sequence. TGGE, with its 'one sequence-one band' detection, reduces the sequence-specific information and might offer new useful properties.

\section{METHODS}

Bacterial strains and cultures. All bacterial cultures were obtained from the BCCM/LMG Culture Collection of the Laboratory of Microbiology, University of Ghent, Belgium. All strains used in this study (listed in Table 1) were cultivated aerobically on trypticase soy agar [TSA; $3 \%$ (w/v) trypticase soy broth (BBL) supplemented with $1.5 \%$ (w/v) Bacto agar (Difco)] for $24 \mathrm{~h}$ at $28^{\circ} \mathrm{C}$.

Isolation and purification of bacterial chromosomal DNA. Genomic DNA was prepared as described by Janssen et al. (1996). In short, approximately $30 \mathrm{mg}$ wet weight of cells was scraped off from TSA plates, washed once with $500 \mu \mathrm{l}$ saline (150 mM NaCl, $10 \mathrm{mM}$ EDTA, $\mathrm{pH} \mathrm{8.0)}$ and resuspended in $100 \mu \mathrm{l}$ TE buffer $(10 \mathrm{mM}$ Tris $/ \mathrm{HCl}, 1 \mathrm{mM}$ EDTA, pH 7.6). Cells were lysed and DNA was extracted with Sarkosyl/guanidinium thiocyanate (Sigma) as described by Pitcher et al. (1989). The DNA was finally dissolved in $100 \mu \mathrm{l}$ TE buffer and kept overnight at $4^{\circ} \mathrm{C}$. After an RNAse treatment $(25 \mu \mathrm{l}$ stock culture of $0.25 \mathrm{mg}$ $\mathrm{ml}^{-1}$ and incubation for $1.5 \mathrm{~h}$ at $37^{\circ} \mathrm{C}$ ), the concentration of all DNA solutions was determined on a Uvikon 940 spectrophotometer (Kontron Instruments) by measuring 
$A_{260}\left(1\right.$ absorbance unit $\left.=50 \mu \mathrm{g} \mathrm{ml}^{-1}\right)$. Final DNA preparations were stored at $-20^{\circ} \mathrm{C}$.

Amplification of 165 rRNA sequences and separation by TGGE. PCR was performed in an Amplitron II thermocycler (Barnstead/Thermolyne), using 30 cycles of $94^{\circ} \mathrm{C}$ for $10 \mathrm{~s}$, $56^{\circ} \mathrm{C}$ for $20 \mathrm{~s}$ and $68^{\circ} \mathrm{C}$ for $40 \mathrm{~s}$. Universal bacterial primers U968-GC and L1401 (Nübel et al., 1996) were used for each strain. The primer numbers 968 and 1401 indicate their binding sites according to the 16S rRNA numbering of Escherichia coli (Brosius et al., 1978). Primer U968-GC contains a GC clamp for directed melting during TGGE (Muyzer et al., 1993). The PCR reactions $(10 \mu \mathrm{l})$ contained $10 \mathrm{mM}$ Tris $/ \mathrm{HCl}$ (pH 8.3), $50 \mathrm{mM} \mathrm{KCl}, 3 \mathrm{mM} \mathrm{MgCl}_{2}$, $50 \mu \mathrm{M}$ each of dATP, dCTP, dGTP and dTTP, $50 \mathrm{pmol}$ U968-GC and L1401, 0.25 U Taq DNA polymerase (Life Technologies) and $1 \mu \mathrm{l}$ template DNA. Six microlitres of amplification product was loaded on the gel.

The Diagen TGGE system was used for sequence-specific separation of PCR products. Electrophoresis took place in a $0.8 \mathrm{~mm}$ polyacrylamide gel $[6 \%(\mathrm{w} / \mathrm{v})$ acrylamide, $0.1 \%$ (w/v) bis-acrylamide, $8 \mathrm{M}$ urea, $20 \%(\mathrm{v} / \mathrm{v})$ formamide, $2 \%$ $(\mathrm{v} / \mathrm{v})$ glycerol] with $1 \times$ TAE (Sambrook et al., 1989) buffer at $9 \mathrm{~mA}$ fixed current (about $125 \mathrm{~V}$ ) for $16 \mathrm{~h}$. A temperature gradient was built up in the electrophoresis direction from 39 to $48^{\circ} \mathrm{C}$. After the run, gels were silver-stained (Sanguinetti et al., 1994).

Fatty acid methyl ester (FAME) analysis. A loopful of wellgrown cells was harvested, and FAMEs were prepared, separated by GLC and identified using the Microbial Identification System software package version 3.9 as described by Vandamme et al. (1992).

\section{RESULTS}

\section{TGGE analysis}

Analysis of $16 \mathrm{~S}$ rDNA sequences from 115 different coryneform bacterial strains was performed by partial amplification of the 16S rRNA genes (positions 968-1401) by PCR with bacteria-specific primers. Sequence-specific separation of amplicons by TGGE and visualization by silver staining allowed the comparison of signals (Figs 1-3). Pure cultures usually produce a single band in TGGE analysis. In Fig. 1, all the different TGGE signals obtained in this study are compiled on one gel. As summarized in Table 1, the left-hand side of Fig. 1 represents PCR products of all authentic strains of the eight genera. These signals are considered to be characteristic for each genus because they are produced by at least one authentic type strain of a species in the genus. Signals from lanes 1-8 are considered to be dissident or atypical because they were defined as unique signals within a genus, not represented by an authentic type strain (Table 1). Lanes 3 and 4 contain the type strains of Arthrobacter picolinophilus and Arthrobacter siderocapsulatus, respectively. However, both taxa are considered to be dissident, because it was further demonstrated that strains of these taxa are generically misclassified (see below). In the course of our studies we observed the appearance of PCR side-products, resulting in faint, additional bands on TGGE. They could be visualized

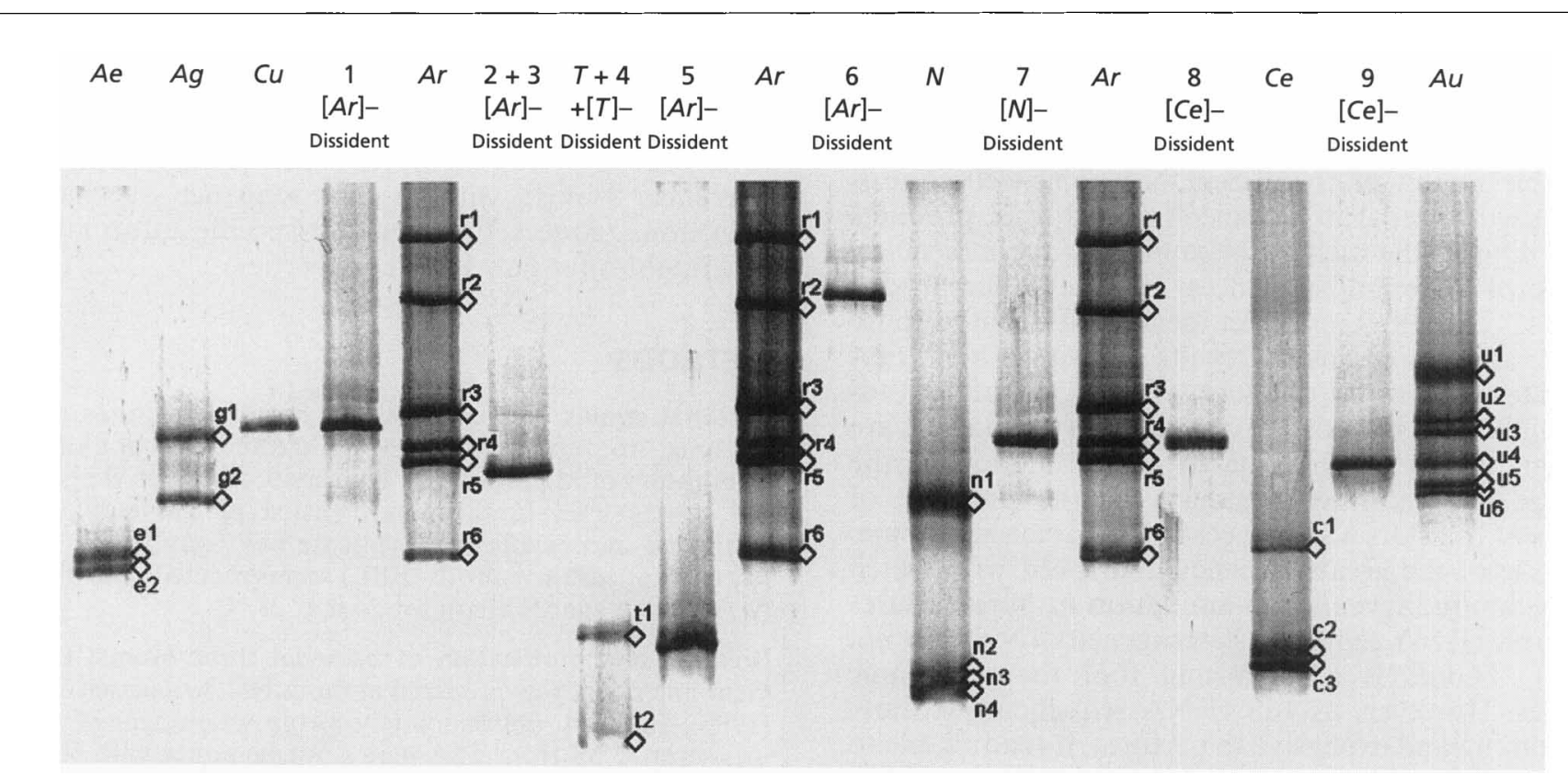

Fig. 1. Silver-stained gel showing TGGE signals of the strains investigated ( $6 \mu 10$-fold diluted product per lane). All authentic signals for the studied genera are compiled in the lanes labelled with the genus abbreviation (Ae, Aeromicrobium; Ag, Agromyces; Cu, Curtobacterium; T, Terrabacter (signal t1); N, Nocardioides; Ar, Arthrobacter; Ce, Cellulomonas; and $\mathrm{Au}$, Aureobacterium). There are several bands per lane because several PCR products were loaded (labels refer to Table 1). Where several strains form the same signal only one representative is loaded, as indicated in Table 1 (bold strains are loaded on this gel). The nine dissident signals are numbered as follows: 1, Arthrobacter ilicis LMG 7255; 2+3, Arthrobacter siderocapsulatus LMG 16118, LMG 16206 ${ }^{\top} ; T+4$, $T$. tumescens LMG 16133 (signal t2); 5 , Ar. picolinophilus LMG $16262^{\top} ; 6$, Arthrobacter globiformis LMG 3820; 7, Nocardioides simplex LMG 3810; 8, Cellulomonas fimi LMG 16132; 9, Cellulomonas turbata LMG 16346 (see also Fig. 2). 


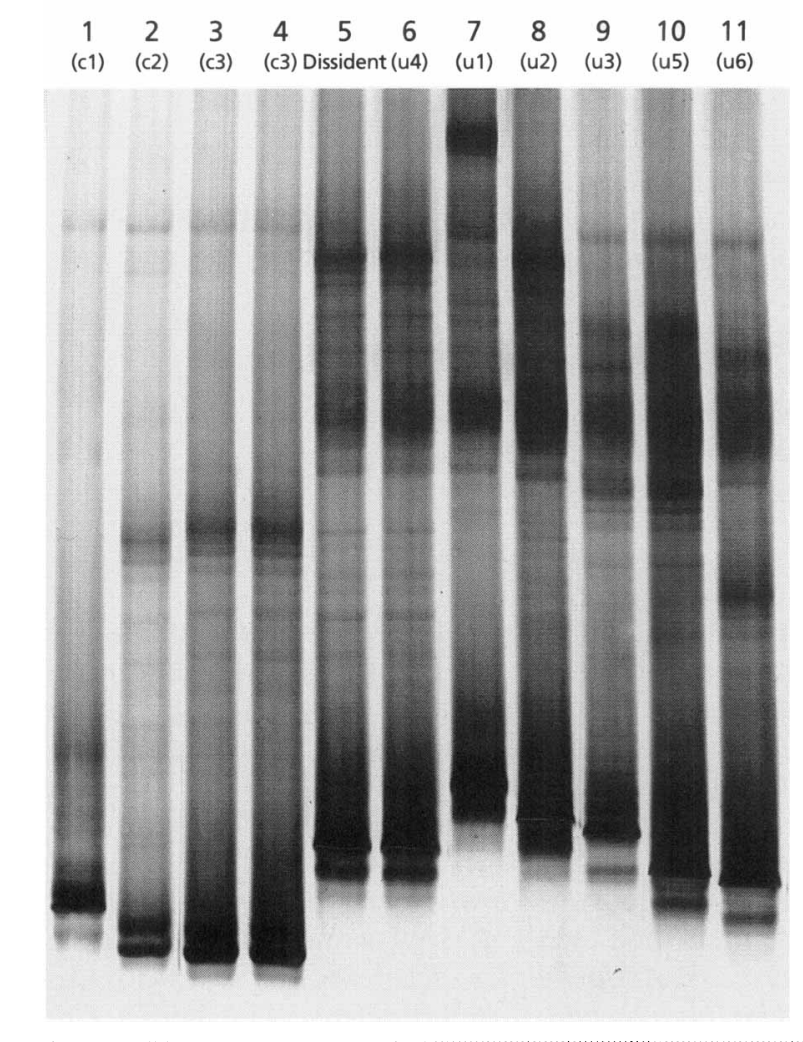

Fig. 2. TGGE signals and genus-specific side-product patterns ( $6 \mu \mathrm{l}$ PCR product per lane) of four authentic Cellulomonas strains (lanes: 1, Cellulomonas cellulans LMG 16221 ${ }^{\top} ; 2$, Cellulomonas fimi LMG $16345^{\top}$; 3, Cellulomonas turbata LMG 16191; 4, Cellulomonas turbata LMG 4072'); six authentic Aureobacterium strains (lanes: 6, Aureobacterium luteolum LMG $16207^{\top}$; 7, Aureobacterium trichothecenolyticum LMG $16696^{\top} ; 8$, Aureobacterium testaceum LMG $16344^{\top} ;$ 9, Aureobacterium terrae LMG $16471^{\top}$; 10, Aureobacterium arabinogalactanolyticum LMG $16469^{\top}$; and 11 , Aureobacterium barkeri LMG $16341^{\top}$ ) and one misclassified strain Cellulomonas turbata LMG 16346 (lane 5).

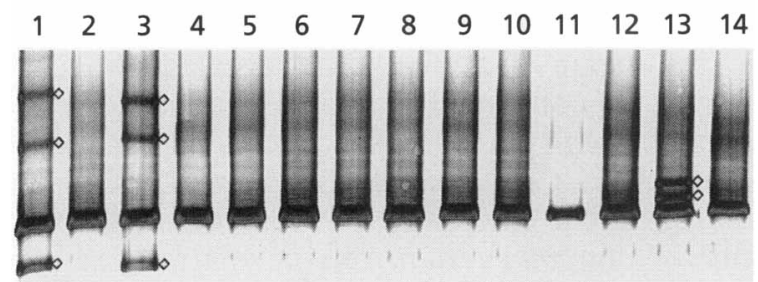

Fig. 3. TGGE signals ( $6 \mu l$ PCR product per lane) of 14 investigated Curtobacterium strains. Lanes: 1, Curtobacterium albidum LMG $8759^{\top}$; 2 , Curtobacterium citreum LMG 16240; 3, Curtobacterium citreum LMG $8786^{\top}$; 4, Curtobacterium flaccumfaciens LMG 3596; 5, Curtobacterium flaccumfaciens LMG 7241; 6, Curtobacterium flaccumfaciens LMG $3645^{\top} ; 7$, Curtobacterium flaccumfaciens LMG 3650; 8 , Curtobacterium flaccumfaciens LMG 3702; 9, Curtobacterium flaccumfaciens LMG 3704; 10, Curtobacterium flaccumfaciens LMG 3710; 11, Curtobacterium flaccumfaciens LMG 3715; 12, Curtobacterium luteum LMG $8787^{\top}$; 13 , Curtobacterium pusillum LMG $8788^{\top}$; 14, Curtobacterium pusillum, LMG 8812. 16S rRNA sequence heterogeneities are revealed and marked in lanes 1, 3 and 13. by loading $6 \mu$ l original PCR product (Figs 2 and 3) instead of $6 \mu 1$ 10-fold diluted PCR product (Fig. 1).

Signals of the type strains of both Aeromicrobium species, Aeromicrobium erythreum and Aeromicrobium fastidiosum, could be separated on TGGE, and their migration distances are quite similar (Fig. 1, lane $A e$ ).

Eight strains of three different Agromyces species were investigated (Table 1). PCR products of Agromyces cerinus and Agromyces fucosus migrated to the same position. Agromyces ramosus could be clearly separated from the other species (Fig. 1, lane $A g$ ).

The 45 investigated Arthrobacter strains, assigned to 21 different species, showed 10 different band positions (Table 1; Fig. 1, lanes $A r$ and 1-4). Three of the signals in lane $A r$ each seem to be characteristic for a single species, i.e. Arthrobacter crystallopoietes (band r2, one strain), Arthrobacter sulfureus (band r5, three strains) and Arthrobacter atrocyaneus (band r6, one strain). Bands r1, r3 and r4 were formed by strains of various species. The same band position (band rl) was obtained for two strains of Arthrobacter citreus and one strain of Arthrobacter viscosus (not the type strain). Band $\mathrm{r} 3$ contained signals of one strain of Arthrobacter citreus (not the type strain) and all strains studied of the species Arthrobacter mysorens, Arthrobacter nicotianae, Arthrobacter protophormiae and Arthrobacter uratoxydans. Band $\mathrm{r} 4$ comprised the signals of at least the type strain, and in some cases one or two additional strains, of the species Arthrobacter aurescens, Arthrobacter globiformis, Arthrobacter histidinolovorans, Arthrobacter ilicis, Arthrobacter nicotinovorans, Arthrobacter oxydans, Arthrobacter pascens, Arthrobacter polychromogenes, Arthrobacter ramosus and Arthrobacter ureafaciens. Four different bands were produced by the dissident strains Arthrobacter globiformis LMG 3820, Arthrobacter ilicis LMG 7255, Arthrobacter picolinophilus $\mathrm{LMG} 16262^{\mathrm{T}}$ and two investigated strains of Arthrobacter siderocapsulatus (Fig. 1, lanes $1,2+3,5$ and 6$)$.

The 19 strains of 11 different Aureobacterium species formed six different bands (Table 1; Fig. 1, lane $A u$ ). As all positions represented at least one type strain, all signals are considered to be characteristic for the genus. Separate signals are observed for the species Aureobacterium trichothecenolyticum (band u1), Aureobacterium testaceum (band u2), Aureobacterium arabinogalactanolyticum (band u5) and Aureobacterium barkeri (band u6). One band (u3) is formed by all investigated strains of Aureobacterium keratanolyticum, Aureobacterium liquefaciens, Aureobacterium luteolum, Aureobacterium saperdae and the type strain of Aureobacterium schleiferi, and another band (u4) is produced by both investigated strains of Aureobacterium esteraromaticum and Aureobacterium terrae and one strain (not the type strain) of Aureobacterium schleiferi. The genus Aureobacterium apparently forms a very clear, specific side-product band pattern (Fig. 2) that seems to be constant for all strains studied. 
Table 2. FAME identification of strains with atypical TGGE signals using the commercial MIS database (version 3.9)

\begin{tabular}{|lll|}
\hline Species name as received & \multicolumn{1}{c|}{ Strain no. } & FAME identification (similarity of first choice) \\
\hline Arthrobacter globiformis & LMG 3820 & Nocardia asteroides $(0 \cdot 068)$ \\
Arthrobacter ilicis & LMG 7255 & Curtobacterium flaccumfaciens pv. oortii $(0 \cdot 291)$ \\
Arthrobacter picolinophilus & LMG $16262^{\mathrm{T}}$ & Rhodococcus erythropolis $(0 \cdot 657)$ \\
Arthrobacter siderocapsulatus & LMG 16118 & Pseudomonas putida biotype A $(0 \cdot 846)$ \\
Arthrobacter siderocapsulatus & LMG $16206^{\mathrm{T}}$ & Pseudomonas putida biotype A $(0 \cdot 650)$ \\
Cellulomonas fimi & LMG 16132 & Arthrobacter pascens $(0 \cdot 476)$ \\
Cellulomonas turbata & LMG 16346 & Aureobacterium esteroaromaticum $(0 \cdot 845)$ \\
Nocardioides simplex & LMG 3810 & Arthrobacter oxydans $(0 \cdot 524)$ \\
Terrabacter tumescens & LMG 16133 & Rhodococcus equi $(0 \cdot 586)$ \\
\hline
\end{tabular}

Five bands were formed by 17 strains of eight different Cellulomonas species (Table 1). Three of them were formed by strains of at least two species, including their type strain, and are considered to be characteristic for the genus (Fig. 1, lane $\mathrm{Ce}$ ). Band $\mathrm{cl}$ was formed by strains of Cellulomonas cellulans and Cellulomonas $u d a$, band $\mathrm{c} 2$ contained signals of two strains of Cellulomonas fimi (including the type strain), both studied strains of Cellulomonas gelida and the type strain of Cellulomonas flavigena, and band c3 was formed by the species Cellulomonas biazotae, Cellulomonas cellasea and two of the three strains of Cellulomonas turbata (including the type strain). Two other bands were formed by single dissident strains: Cellulomonas turbata LMG 16346 (Fig. 1, lane 9) and Cellulomonas fimi LMG 16132 (Fig. 1, lane 8).

All 14 investigated Curtobacterium strains gave the same main TGGE band (Fig. 1, lane $C u$ ) and also the same side-product pattern type (Fig. 3). This might indicate that the five different species contain an (almost) identical 16S rRNA sequence. Three strains, Curtobacterium albidum LMG $8759^{\mathrm{T}}$, Curtobacterium citreum LMG $8786^{\mathrm{T}}$ and Curtobacterium pusillum LMG $8788^{\mathrm{T}}$, are not presented in Fig. 1 because they showed two or three more bands, indicating 16S rRNA gene heterogeneity (Fig. 3, lanes 1, 3 and 13).

Eight strains of four Nocardioides species were investigated. Each of the four bands that characterize the genus was formed by a single species, i.e. Nocardioides jensenii, Nocardioides simplex, Nocardioides albus and Nocardioides luteus (Fig. 1, lane $N$; Table 1). In addition, the genus Nocardioides formed a prominent, specific side-product band pattern (data not shown). The dissident strain Nocardioides simplex LMG 3810 gave a separate signal (Fig. 1, lane 7).

Two strains assigned to the species Terrabacter tumescens were investigated. Different bands were formed by the type strain (Fig. 1, lane $T+4$, band 1 ) and one aberrant strain (Fig. 1 , lane $T+4$, band $t 2$ ).

\section{Classification of dissident strains}

All strains of the present study were also investigated by cellular fatty acid analysis (data not shown). This revealed that only strains producing dissident TGGE signals phylogenetically belong to a different genus from the one in which they are currently classified. Profiles of dissident strains were identified with the commercial MIS database (version 3.9). The results are summarized in Table 2. Four of the Arthrobacter strains were classified by FAME analysis in different genera (Table 2). Arthrobacter globiformis LMG 3820 was identified with a low similarity as Nocardia asteroides. Arthrobacter ilicis LMG 7255 was identified as Curtobacterium flaccumfaciens. The genus Curtobacterium was included in our study, and it was indeed confirmed that Arthrobacter ilicis LMG 7255 produced a signal characteristic for the genus Curtobacterium (Fig. 1, lane 1, shows Arthrobacter ilicis LMG 7255; directly next to it on the left-hand side in lane $\mathrm{Cu}$ ). Arthrobacter picolinophilus LMG $16262^{\mathrm{T}}$ was identified with a high identification score as Rhodococcus erythropolis and confirmed the data of Koch et al. (1995a), who reclassified the organism in the latter taxon. Both investigated strains of Arthrobacter siderocapsulatus (lane 4) were identified as Pseudomonas putida using FAME analysis. Concerning aberrant Cellulomonas strains, Cellulomonas fimi, LMG 16132 was identified by FAME analysis as Arthrobacter pascens and Cellulomonas turbata LMG 16346 as Aureobacterium esteroaromaticum (Table 2). In each case, the strain identifications revealed by FAME analysis were confirmed by TGGE analysis; the band positions were $\mathrm{r} 4$ and $\mathrm{u} 4$, respectively (Fig. 1; Table 1). Additionally, Cellulomonas turbata LMG 16346 demonstrated a side-band pattern identical to that found for Aureobacterium reference strains (Fig. 2). One dissident strain of the genus Nocardioides, Nocardioides simplex LMG 3810, was identified as Arthrobacter oxydans using FAME analysis and indeed produced a TGGE signal at the same migration distance as band r4 of Arthrobacter (Fig. 1, lane 7, shows Nocardioides simplex LMG 3810 ; directly next to it on the right-hand side lane $A r$ ). Strain Terrabacter tumescens LMG 16133, identified as Rhodococcus equi using FAME analysis, produced a different signal (Fig. 1, lane $T+4$, band $t 2$ ) from that of the type strain (Fig. 1, lane $T+4$, band $\mathrm{t} 1$ ). 


\section{DISCUSSION}

\section{Taxonomic significance of TGGE analysis}

The present study demonstrates that TGGE may be a convenient and alternative screening method in polyphasic taxonomy that allows reliable taxonomic conclusions to be drawn. The resolution limit of this technique appears to be somewhere between the genus and species level. The 16S rDNA fragment amplified here (primers U968-GC and L1401) could be separated by only 1 bp sequence difference (Nübel et al., 1996). Depending on the genus investigated, signals were species-specific (e.g. Nocardioides), specific for several species of the genus (e.g. Cellulomonas) or genusspecific (e.g. Curtobacterium). In all cases, aberrant TGGE signals of strains of a single species indicated misclassifications.

When comparing TGGE banding patterns with available 16S rRNA sequence data of reference strains, some preliminary conclusions concerning the applicability of TGGE in phylogenetic studies may be drawn. Within the genus Arthrobacter, the TGGE signals r1-r6 (Fig. 1, lanes $A r$ ) were created by strains of one or more authentic species of the genus and were compared with the phylogenetic distances of the $16 \mathrm{~S}$ rRNA sequences of these species (Koch et al., 1995b). In both approaches, the species Arthrobacter atrocyaneus and Arthrobacter crystallopoietes occupy a clearly separate position. Furthermore, Arthrobacter nicotianae, Arthrobacter protophormiae and Arthrobacter uratoxydans, which constitute band $\mathrm{r} 3$, are all classified into rRNA group II (species with peptidoglycan type A4 $\alpha$ ), and species Arthrobacter aurescens, Arthrobacter globiformis, Arthrobacter histidinolovorans, Arthrobacter ilicis, Arthrobacter nicotinovorans, Arthrobacter oxydans, Arthrobacter polychromogenes, Arthrobacter ramosus and Arthrobacter ureafaciens are all classified in rRNA group I (peptidoglycan type $\mathrm{A} 3 \alpha$ ). When comparing sequencing data of Cellulomonas species (Funke et al., 1995) with data from the present study, less analogy is observed. Species that are phylogenetically more closely related do not always exhibit a similar TGGE signal. Within the genus Agromyces, a more distant relationship of the species Agromyces ramosus is also supported by the 16S rRNA phylogeny (Suzuki et al., 1996). However, it should be remembered that, with TGGE, the migration distance of amplicons, i.e. the distance between two different bands, is not correlated with the degree of nucleobase difference between the sequences. The migration of amplicons in TGGE depends on the melting behaviour of the molecule, and a nucleobase exchange might have quite different effects, depending on its position within the sequence.

The application of TGGE for taxonomic characterization is most effective in the fast screening of large numbers of pure cultures. For example, dozens of environmental isolates identified by classic microscopical and biochemical analyses as Arthrobacter species could be subjected to further analysis. A typical procedure would be to reactivate the strains by transferring cell material from frozen or lyophilized storage samples to fresh culture media. As bacterial cells multiply exponentially, this is a crucial step. For instance, one particular strain may have suffered during sample preparation or storage, resulting in poor viability and leaving only a few surviving cells to grow with an extended lag phase. In this situation, fast-growing contaminants might easily outcompete the original strains during culture. As an increasing number of strains are investigated, the 'human factor' also becomes more and more important. During handling, samples could be confused and the pressure to increase the speed of even 'routine' processing might result in less efficient sterilization of equipment. TGGE is helpful in this respect in that it can readily establish the authenticity of batch cultures, both by confirming the original identification obtained by classical methods and by enabling subsequent cultivation procedures that might be affected by contamination to be monitored. After DNA extraction from batch culture samples and subsequent PCR, the strains could be compared with the six Arthrobacter signals identified in this study (Fig. 1, lane $A r$ ). Mismatches would be considered as suspicious, possibly caused by a wrong previous identification or contamination of the original strain. The latter could be verified by comparison with a PCR product from the original storage sample. However, it would not be possible to exclude the possibility that some novel members of the genus Arthrobacter might result in a seventh (or more) band position. The aberrant signals on TGGE can reliably indicate bias during strain processing or novel sequences in the culture collection concerned.

\section{5 rRNA gene heterogeneity}

TGGE is the optimal tool to unveil 16S rRNA gene heterogeneity. Of the 115 strains investigated, additional strong signals were detected in three Curtobacterium strains, indicating 16S rRNA gene heterogeneity (Fig. 3, lanes 1, 3 and 13). Amplicons from pure cultures show one band if all copies of the $16 \mathrm{~S}$ rDNA in the bacterial genome have an identical sequence. The appearance of more than one strong band indicates heterogeneity of 16S rRNA genes in the genome. Although only about the last third of the $16 \mathrm{~S}$ rRNA (including variable regions V6-V8) was studied, our screens of 115 strains are the most comprehensive performed to date. The finding of only three positive Curtobacterium strains indicates that 16S rRNA sequence heterogeneity is not very common within the coryneform bacteria. This phenomenon has been reported previously for Paenibacillus polymyxa (Nübel et al., 1996). Therefore, studies involving Curtobacterium or Paenibacillus strains should consider possible 16S rRNA gene heterogeneity, which might confuse 16S rRNA analysis. 
It should be remembered that additional bands can also represent contamination of the original culture. In the case of gene heterogeneity, bands are often arranged close to each other (Nübel et al., 1996), at more or less constant intervals ('ladder-like'). Additional bands of identical intensity or whose intensity is identical to that of the 'main band' also indicate gene heterogeneity (sequences that are present in the same copy number yield products of identical intensity). Additional bands that vary greatly in their intensity are more likely to represent contamination of the original culture than 16S rRNA sequence heterogeneity. Also, signals due to gene heterogeneity within a pure culture will remain stable during different subculture, whereas a mixed culture will probably shift its composition and consequently change its TGGE band pattern upon subculturing.

In addition to culture-specific contamination and species-specific signal heterogeneity, a third group of apparently genus-specific additional bands might be observed. We found that the main bands, attributable to the 16S rDNA amplicons, were often accompanied by faint, but reproducible, band patterns of variable complexity (Figs 2 and 3 ). These became increasingly visible when the gels were loaded with increasing amounts of PCR product. Most likely these signals represent sequence-specific DNA polymerization artefacts. Those side-products showed genus-specific patterns and varied between different species only by position. Side-product formation could be an additional indicator of sequence identity. One example has been demonstrated: Cellulomonas strain LMG 16346 produced a banding pattern that was similar to that of the genus Aureobacterium, an identification that was confirmed using other approaches (see above; Fig. 2, lanes 4 and 5).

\section{Conclusions}

TGGE and the similar technique DGGE are attractive methods for the analysis of mixed cultures or environmental bacterial communities. After separation of the 16S rRNA sequence mixture in electrophoretic fingerprints (Muyzer et al., 1993), the single signals in such a band pattern could be identified by comparison with pure culture signals (Rölleke et al., 1996) or clone libraries (Felske et al., 1997). The present study shows that this technique could also be used to assess the identity of pure cultures. The resolution limit for the taxonomic TGGE analysis appears to be between the genus and species level. Dissident signals reliably revealed misclassified strains and by chance also pointed to the real identity of the misfits. TGGE is also a fast and powerful method to reveal 16S rDNA gene heterogeneity in bacterial strains. This is especially important for subsequent sequencing of the $16 \mathrm{~S}$ rRNA genes. Comparative TGGE has been demonstrated to be a useful tool for taxonomic studies, particularly where large sets of bacterial cultures are screened.

\section{ACKNOWLEDGEMENTS}

This work was supported by the European Communities EC project 'High Resolution Automated Microbial Identification' (EC-HRAMI project BIO2-CT94-3098). Part of this research was supported by the Prime Minister's Services Federal Office for Scientific, Technical and Cultural Affairs, Belgium.

\section{REFERENCES}

Brosius, J., Palmer, M. L., Kennedy, P. J. \& Noller, H. F. (1978). Complete nucleotide sequence of a 16S ribosomal RNA gene from Escherichia coli. Proc Natl Acad Sci USA 75, 4801-4805.

Buchholz-Cleven, B. E. E., Rattunde, B. \& Straub, K. L. (1997). Screening for genetic diversity of isolates of anaerobic Fe(II)oxidizing bacteria using DGGE and whole-cell hybridization. Syst Appl Microbiol 20, 301-309.

BioTechniques 17, 915-919.

Colwell, R. R. (1970). Polyphasic taxonomy of bacteria. In Proceedings of the International Conference on Culture Collections, pp. 421-436. Edited by H. Iizuka \& T. Hasegawa. Tokyo: Tokyo University Press.

Felske, A., Rheims, H., Wolterink, A., Stackebrandt, E. \& Akkermans, A. D. L. (1997). Ribosome analysis reveals prominent activity of an uncultured member of the class Actinobacteria in grassland soils. Microbiology 143, 2983-2989.

Ferris, M. J., Muyzer, G. \& Ward, D. M. (1996). Denaturing gradient gel electrophoresis profiles of $16 \mathrm{~S}$ rRNA-defined populations inhabiting a hot spring microbial mat community. Appl Environ Microbiol 62, 340-346.

Fischer, S. G. \& Lerman, L. S. (1979). Length-independent separation of DNA restriction fragments in two-dimensional gel electrophoresis. Cell 16, 191-200.

Funke, G., Ramos, C. P. \& Collins, M. D. (1995). Identification of some clinical strains of CDC Coryneform Group A-3 and A-4 bacteria as Cellulomonas species and proposal of Cellulomonas hominis sp. nov, for some group A-3 strains. J Clin Microbiol 33, 2091-2097.

Janssen, P., Coopman, R., Huys, G., Swings, J., Bleeker, M., Vos, P., Zabeau, M. \& Kersters, K. (1996). Evaluation of the DNA fingerprinting method AFLP as a new tool in bacterial taxonomy. Microbiology 142, 1881-1893.

Koch, C., Klatte, S., Schumann, P., Burghardt, J., Kroppenstedt, R. M. \& Stackebrandt, E. (1995a). Transfer of Arthrobacter picolinophilus Tate and Ensign 1974 to Rhodococcus erythropolis. Int $J$ Syst Bacteriol 45, 576-577.

Koch, C., Schumann, P. \& Stackebrandt, E. (1995b). Reclassification of Micrococcus agilis (Ali-Cohen 1889) to the genus Arthrobacter as Arthrobacter agilis comb. nov. and emendation of the genus Arthrobacter. Int J Syst Bacteriol 45, 837-839.

Muyzer, G., De Waal, E. C. \& Uitterlinden, A. G. (1993). Profiling of complex microbial populations by denaturing gradient gel electrophoresis analysis of polymerase chain reaction-amplified genes coding for 16S rRNA. Appl Environ Microbiol 59, 695-700.

Mylvaganam, S. \& Dennis, P. P. (1992). Sequence heterogeneity between the two genes encoding 16S rRNA from the halophilic archaebacterium Haloarcula marismortui. Genetics 130, 399410.

Nübel, U., Engelen, B., Felske, A., Snaidr, J., Wieshuber, A., Amann, R. I., Ludwig, W. \& Backhaus, H. (1996). Sequence heterogeneities of genes encoding 16S rRNAs in Paenibacillus 
polymyxa detected by temperature gradient gel electrophoresis. $J$ Bacteriol 178, 5636-5643.

Pitcher, D. G., Saunders, N. A. \& Owen, R. J. (1989). Rapid extraction of bacterial genomic DNA with guanidinium thiocyanate. Lett Appl Microbiol 8, 151-156.

Rölleke, S., Muyzer, G., Wawer, C., Wanner, G. \& Lubitz, W. (1996). Identification of bacteria in a biodegraded wall painting by denaturing gradient gel electrophoresis of PCR-amplified 16S rDNA fragments. Appl Environ Microbiol 62, 2059-2065.

Rosenbaum, V. \& Riesner, D. (1987). Temperature-gradient gel electrophoresis - thermodynamic analysis of nucleic acids and proteins in purified form and in cellular extracts. Biophys Chem 26, 235-246.

Sambrook, J., Fritsch, E. F. \& Maniatis, T. (1989). Molecular Cloning : a Laboratory Manual, 2nd edn. Cold Spring Harbor, NY: Cold Spring Harbor Laboratory.

Sanguinetti, C. J., Dias Neto, E. \& Simpson, A. J. (1994). Rapid silver staining and recovery of PCR products separate on polyacrylamide gels. BioTechniques 17, 915-919.

Schleifer, K. H. \& Stackebrandt, E. (1983). Molecular systematics of prokaryotes. Annu Rev Microbiol 37, 143-187.

Stackebrandt, E. \& Kandler, O. (1979). Taxonomy of the genus Cellulomonas, based on phylogenetic characters and deoxyribonucleic acid - deoxyribonucleic acid homology, and proposal of seven neotype strains. Int J Syst Bacteriol 29, 273-282.

Stackebrandt, E., Rainey, F. A. \& Ward-Rainey, N. L. (1997). Proposal for a hierarchic classification system of Actinobacteria classis nov. Int J Syst Bacteriol 47, 479-491.
Suzuki, K.-I., Sasaki, J., Uramoto, M., Nakase, T. \& Komagata, K. (1996). Agromyces mediolanus sp. nov., rev., comb. nov., a species for 'Corynebacterium mediolanum' Mamoli 1939 and for some aniline-assimilating bacteria which contain 2,4diaminobutyric acid in the cell wall peptidoglycan. Int $J$ Syst Bacteriol 46, 88-93.

Teske, A., Wawer, C., Muyzer, G. \& Ramsing, N. B. (1996). Distribution of sulfate-reducing bacteria in a stratified fjord (Mariager Fjord, Denmark) as evaluated by most-probablenumber counts and DGGE of PCR-amplified ribosomal DNA fragments. Appl Environ Microbiol 62, 1405-1415.

Vandamme, P., Vancanneyt, M., Pot, B. \& 10 other authors (1992). Polyphasic taxonomic study of the emended genus Arcobacter with Arcobacter butzleri comb. nov. and Arcobacter skirrowii sp. nov., an aerotolerant bacterium isolated from veterinary specimens. Int $J$ Syst Bacteriol 42, 344-356.

Vandamme, P., Pot, B., Gillis, M., De Vos, P., Kersters, K. \& Swings, J. (1996). Polyphasic taxonomy, a consensus approach to bacterial systematics. Microbiol Rev 60, 407-438.

Vaneechoutte, M., Rossau, R., De Vos, P. \& 7 other authors (1992). Rapid identification of bacteria of the Comamonadaceae with amplified ribosomal DNA-restriction analysis (ARDRA). FEMS Microbiol Lett 93, 227-234.

Welsh, J. \& McClelland, M. (1990). Fingerprinting genomes using PCR wtih arbitrary primers. Nucleic Acids Res 18, 7213-7218.

Woese, C. R. \& Fox, G. E. (1977). Phylogenetic structure of the prokaryotic domain: the primary kingdoms. Proc Natl Acad Sci USA 74, 5088-5090. 